\title{
Being denied and granted social welfare and the propensity to protest
}

\author{
Maria Theiss $^{1} \cdot$ Anna Kurowska $^{1}$
}

Published online: 13 April 2018

(C) The Author(s) 2018

\begin{abstract}
The article examines the effects that positive and negative experiences with applying for social welfare have on the individual's propensity to protest. We investigate how being denied or granted social benefits or services as well as the interaction of these two experiences influences self-reported prospective protest behaviour. We also explore the moderating role of one's financial situation on these effects. Referring to the scholarship on protest motivations and emotions as well as on policy feedback, we hypothesise that receiving social welfare might have a different impact on the propensity to protest, depending on the other experiences people have had with the welfare state. In order to verify the hypotheses, we use survey data from nine European countries, gathered within the LIVEWHAT project. One of the major findings is that, although both being denied and being granted benefits or service positively affect the propensity to protest, the experience of receiving benefits moderates the impact of being denied benefit/service on prospective protesting among those living in poverty.
\end{abstract}

Keywords Political protest $\cdot$ Social benefits · Policy feedback · Grievances · Benefit denial

Maria Theiss

m.theiss@uw.edu.pl

Anna Kurowska

a.kurowska@uw.edu.pl

1 University of Warsaw, Warsaw, Poland 


\section{Introduction}

Welfare state institutions considerably influence citizens' political behaviour, including protest activities, which may be triggered by welfare cuts, or by resources being redistributed to individuals and social groups, or collective identities imposed on welfare beneficiaries. Contemporary changes in European welfare states become increasingly complex and incoherent. Citizens' mixed experiences, whereby they receive some social welfare while at the same time being denied some benefits or services, as well as problems in accessing social services among welfare state users are widespread (see e.g. Schneider and Devitt 2017; Avram 2016; van Lancker 2017).

In particular, two mechanisms may result in the common experience of a welfare state concurrently granting and withholding help. First, austerity measures introduced in response to Europe's economic crisis, e.g. in Greece or Spain, eroded social citizenship and the growth of conditionality (Marchal et al. 2014; Yerkes and van der Veen 2011), both of which mainly affected vulnerable groups of citizens. However, protective measures have also been employed, leading some scholars to claim that the welfare state has been reshaped (Vis et al. 2013) or reframed (Taylor-Gooby 2009) rather than only retrenched. Second, far-reaching welfare reforms implemented by populist governments have contributed to the restructuring of social rights. Poland is a case in point: In 2015, it introduced a generous family benefit for households with previously limited access to social welfare, while at the same time putting an end to some reproductive healthrelated services (Szelewa 2017).

In this article, we argue that being denied benefits or services (hereinafter also referred to as 'social welfare') and receiving social welfare in some other form constitutes a specific reason for protest behaviour. According to existing studies in general, being denied benefits or services drives people to protest, but receiving social welfare empowers them to take political action in the form of political protest as well (Muñoz et al. 2014; Lorenzini and Giugni 2015; Quaranta 2014). Our major goal is to test the hypothesis that there is no simple additive mechanism between those experiences-people who receive social welfare while at the same time being refused state support which they think they deserve are not more prone to protest than those who have only been refused support from the state. This can be attributed to social welfare's multifaceted impact on protest behaviour. Social services and benefits endow individuals with resources, social networks, collective identities and a sense of citizenship and thus stimulate them to engage in unconventional political participation. However, those same services and benefits alter the perception of how the welfare state operates, ameliorate feelings of injustice and dismantle the collective identity of the underprivileged. This, in turn, tempers the motivation to protest among those, who have been denied welfare.

Although there is a robust literature on the effects of the European economic crisis of 2008 and subsequent austerity measures on collective protest action and new social movements (Giugni and Grasso 2015b; Genovese et al. 2016; della 
Porta and Mattoni 2014), research linking individual citizens' experiences with a crisis-affected welfare state to political participation is still limited (with such exceptions as collection of Kumlin 2014 and Grasso and Giugni 2016). Within this literature, the effects of resources obtained from the welfare state on protest behaviour have been investigated, e.g. by Lorenzini and Giugni (2015) and Quaranta (2014). Significantly fewer studies have focused on the impact of being refused a benefit or social service, though Muñoz et al. (2014) have weighed in. Beyond their work, there has been a lack of analyses on the interaction between the fact of being denied a service or benefit and that of receiving them. With this article, we seek to begin addressing the research gap on the impact of individuals' diverse experiences with the welfare state on their propensity to protest.

To do so, we connect two streams of scholarship. The first is the integrative approach of van Stekeleburg and Klandermans (2013; van Stekelenburg et al. 2011), who investigate the connection between grievances (Gurr 1970; Klandermans et al. 2015) and resources (Verba et al. 1995; Norris 2002; Quaranta 2014), as well as the motivations and emotions that lead to protest, with the focus on the latter aspect (see also Cinalli and Vasilopoulos 2015). The second stream is the literature on policy feedback (Pierson 1993; Campbell 2012), and in particular its insights into the impact of social welfare on political participation (rather than understanding of how political attitudes and behaviours change policies). We refer to these two streams because understanding protest behaviour demands a complex approach to analysing particular stimuli within various contexts that may alter the meaning of those stimuli (van Stekeleburg and Klandermans 2013), whereas our analysis focuses on the role of specific social policy-related incentives to protest.

This article builds upon the results of an international survey conducted in 2015 in nine European countries on a sample of 18,370 respondents. Retrospective questions were used to measure the experience of receiving and being denied social benefits or services, while forward-looking questions designed to determine whether the interviewee is likely to engage in protest or demonstration were used to gauge the propensity to protest. The remainder of this article is structured as follows. The next section explores hypotheses from the literature on grievances, psychological motivations in protest behaviour and policy feedback. We expect to find positive effects of both being denied and being provided with benefits or services on the propensity to protest. However, we anticipate that the interaction effect between being denied and being provided with benefits or services on the propensity to protest will be negative. Receiving benefits or services will moderate the positive effect of their being denied. We also expect to find that it will be those living in poverty who are particularly affected by the denial of services. The third section presents the data and the variables we used in our survey and the research design, while the fourth presents the results of a series of logistic regression models. In the last section, we discuss the multifarious impact which receiving social welfare has on the propensity to protest with regard to the findings of previous studies. By complex, we mean that it is positive in some contexts and negative in others: receiving benefits or services can increase the propensity to protest, or, when other circumstances prevail, diminish it. 


\section{Theoretical background and hypotheses}

\section{The effect of being denied social welfare on the propensity to protest}

The research analysing the impact of being denied social welfare on the propensity to protest that does exist shows that social welfare cuts or a failure to provide services or benefits individuals think they deserve does compel people to protest. In their study based on an ongoing online panel survey in Spain, Muñoz et al. (2014) show that those who have experienced welfare cuts, such as public sector employees whose salaries have been reduced, report higher levels of political participation (including taking part in demonstrations and strikes) than the rest of the population. Muñoz and his colleagues conclude that while entitlement to social rights and benefits has been shown to empower citizens, the withdrawal of rights and benefits has increased the involvement of those who were affected by them (ibid., p. 37). Similarly, in a study on unemployed youth in Cologne and Geneva, Lorenzini and Giugni (2015) find that although receiving financial aid does not affect the propensity to protest among the individuals in this group, "the probability of engaging in protest activities is higher when one feels he or she has not received the services one is entitled to from the respective state office" (Lorenzini and Giugni 2015, p. 830).

These results are consistent with studies linking the level of satisfaction with the welfare state to the individual propensity to protest. They show that the general negative assessment of social policy (Farah et al. 1979), specific local social policies (Dowding and John 2008) and individual negative experiences with healthcare, childcare or public school (Solevid 2009; Kriesi and Westholm 2007) lead to political protest. Likewise, Solevid (2009) applied a policy feedback perspective to her analysis of the relationship between the satisfaction users of Swedish welfare services felt and the likelihood that they would protest, and found a positive correlation between dissatisfaction with public services and a propensity for political action.

Grievance theory allows us to contextualise these findings in a broader theoretical framework. Classical grievance theories maintain that the rapid failure of economic systems results in grievances which people seek to redress by engaging in political protest (Gurr 1970; Kornhauser 1959). More recent studies, however, have emphasised that it is not economic breakdown itself but rather austerity measures implemented to alleviate it that most lead to protest behaviours (Bermeo and Bartels 2014). When looking at the impact of austerity measures on the individual propensity to protest, relative deprivation mechanisms need to be taken into account. Comparing one's own situation to others' situation or a cognitive standard, such as a normative assumption of what is justified, leads to a relative deprivation which influences the individual's readiness to engage in protest (Gurr 1970; Folger 1986; van Stekeleburg and Klandermans 2013). The causal relation between social welfare denial and protest behaviour, as argued further, may be explained by two factors: the cognitive aspect of deprivation (one is convinced she or he receives less than deserved) and the affective aspect of deprivation, 
which is based on feelings of disaffection or indignation (van Zomeren et al. 2008). We assume that both of these deprivation-related mechanisms follow the experience of being denied social benefit or service. The above studies lead us to formulate hypothesis (H1): The experience of being denied benefit or service increases the propensity to protest.

It may be argued that having one's benefit or service denied constitutes a grievance particularly for poor citizens. Since losing one's benefits may be recognised as meaningful and morally unjustifiable, those who struggle to make ends meet would tend to manifest both mechanisms van Zomeren et al. (2008) described. Anger should be found particularly in this subpopulation, an assumption that is indeed consistent with other studies that prove the impact of social welfare cuts or denial on unconventional political participation is contingent upon group financial vulnerability (Muñoz et al. 2014; Cinalli and Vasilopoulos 2015). We therefore hypothesise that $(\mathrm{H} 2)$ : The effect of the experience of being denied benefits or services on prospective protest behaviour is conditional upon living in poverty.

\section{The effect of receiving social welfare on the propensity to protest}

Because political action requires skills and resources (McCarthy and Zald 1977; Klandermans 1997), social welfare may increase the number of people who participate in protest activities. Brady et al. (1995) showed that time, money and civic skills increase civic participation. Other individual resource-related factors, such as gender, age, education and socioeconomic status have also been confirmed to affect individual political participation (Verba et al. 1995; Teorell et al. 2007; Marien et al. 2010). Thus, a welfare state's role in delivering resources and, more broadly, in reshaping economic inequalities in society is vital in channelling conventional and unconventional political participation. That a welfare state increases political participation has been confirmed on the country level: the more generous and universal the welfare state is, the more widespread civic participation becomes (including protests) at the macro level (Campbell 2003; Dodson 2016; Quaranta 2014; Rothstein 2001). ${ }^{1}$ Similar relationships are present in regard to the individual dimension in society. For example, Mettler has shown the positive effects an educational programme carries for veterans in the US. The programme provided resources based on skills and knowledge, as well as positive symbolic messages (Mettler 2005). However, the literature on social policy feedback shows that the impact of social support on political attitudes and behaviours is multifaceted, and depends on how benefits are constructed, their generosity, visibility, administration and the proximity of beneficiaries (Campbell 2012).

Two main micro-level mechanisms which explain the causal effect of social welfare on political engagement, including protest behaviour, are described in the policy feedback literature (Pierson 1993; Campbell 2003, 2012; Lynch and Myrskyla 2009). First, social benefits endow citizens with resources crucial for protesting,

\footnotetext{
1 However, there are divergent standpoints, which suggest an associative fabric could be crowded out by a generous welfare state (van Oorschot and Arts 2005).
} 
including money, civic skills and other forms of material support (Schur 2003). Newer studies have also examined the role social networks play in mobilisation (Diani and McAdam 2003; van Stekeleburg and Klandermans 2013) and the incentives they provide to interest groups to mobilise beneficiaries by creating a political identity (Campbell 2003, 2012). Second, receiving a social benefit or service also has an interpretive effect. It has been shown that symbolic messages conveyed to social welfare claimants influence their sense of deservingness, membership in the political community, access to common goods and control to shape their internal political efficacy. Lynch and Myrskyla have written that policy feedback effects may work through ideas the same way that policy institutions affect, e.g. public anxieties, beliefs about civic duties, one's own political efficacy and the legitimacy of making claims (Lynch and Myrskyla 2009, p. 8; Campbell 2012). ${ }^{2}$ In the light of the studies described above, we further hypothesise that (H3): Receiving a benefit or service boosts the propensity to protest.

Taking into account the findings about social networks and the collective identity of welfare state beneficiaries, as well as the interpretive effect, which entails a symbolic meaning of obtaining social welfare, we assume that (H4): Receiving a benefit or service will increase the propensity to protest, irrespective of one's financial situation.

\section{The interaction effect of being denied and receiving social welfare on the propensity to protest}

What would be the effect of obtaining social welfare while being denied services or benefits? Should we expect a simple 'additive effect' - that is, expect people (living in poverty) who are denied some benefits or services to be more likely to engage in protest activities than, caeteris paribus, (poor) individuals who have only been denied social welfare? We are not aware of any empirical studies addressing this research question, but we would actually expect a negative interaction effect in this regard.

This expectation is justified by two arguments. The first one results from the growing body of research on policy feedback that seeks to identify the circumstances under which policy feedback fails to emerge. In particular, the works of Patashnik and Zelizer $(2009,2013)$ examine the aspects of program construction and policy context, both of which may hamper policy feedback. They provide evidence that several factors may result in the absence of policy feedback. These include policy design (e.g. related to dysfunctional social construction of target constituency), inadequate or conflicting forms of institutional support for policy and poorly timed policy implementation. While these insights are focused on the explanation of policy stability over time (this aspect being called 'back' by Campbell (2012, p. 347), in contrast to 'feed' within policy feedback scholarship), they clearly show that political protest resulting from policy retrenchment may be muted if it is accompanied by

\footnotetext{
${ }^{2}$ However, the interpretive effect strengthening the individual's civic identity and sense of membership in the polity may have a stronger effect on conventional political participation than on protest behaviour.
} 
other policies which shape contradictory identities of the people affected by austerity measures.

Vanhuysse provides an example of a negative interaction effect when social welfare cuts are made but other social benefits or services continue to be received: the propensity to protest drops (2006). He showed how, after rapid increases in poverty and unemployment in Central and Eastern European in the 1990s, the governments of Poland, Czech Republic and Hungary were able to prevent massive waves of strikes and protests by the strategic use of welfare state programs. Social policies were used to split up highly aggrieved groups of workers by extending unemployment benefits to some and early retirement and disability pensions to many others.

The second argument which speaks to the negative interaction effect between receiving and being denied social welfare results from disentangling the interpretive effect of benefits or services. The literature points to the diversity of interpretive effects caused by obtaining social welfare, depending on policy design (Campbell 2012; Béland 2010). Given that diversity, we conclude that, apart from the positive symbolic messages of inclusion in polity and the sense of civic obligation (the main effect of social welfare), a specific cognitive-emotional interaction effect of obtaining services or benefits emerges if simultaneous experience of social welfare denial takes place. We suppose that when some benefits or services are obtained, while other forms of social welfare are denied, individual feelings of injustice and anger are calmed, thanks to the altered perception of how the welfare state functions. A welfare state which "sometimes gives and sometimes takes away" may well be appreciated more than one which only takes away. Not only may obtaining benefits soothe the individual's anger when he or she has only had negative experiences with the welfare state, but also group anger and group identity. At least in the short term, and in particular during an economic crisis, obtaining social welfare may dismantle the collective identity of the underprivileged — one might have felt solidarity with the unemployed, whose benefits had been cut-until they were granted a generous family benefit.

Although streams of research on policy feedback, protest motivations and the emotions surrounding them remain detached, as Muñoz et al. (2014, p. 20) note, we subscribe to their argument that all three deliver complementary aspects to a broader framework which enables one to understand how the experience of being denied social welfare and obtaining some social welfare interact and influence protest behaviour. Accordingly, we hypothesise that (H5): People who are denied social welfare but receive some (other) benefits or services have a lower propensity to protest than those who are only denied social welfare.

\section{Data and research design}

We used data from an original cross-national survey fielded in 2015 from the 'Living with Hard Times' (LIVEWHAT) project, which was funded by the European Commission under the auspices of their 7th Framework Programme. This database has been used for studies on political action (see e.g. Giugni and Grasso 2017). The survey was conducted by YouGov in each of the nine European countries included 
in the project: France, Germany, Greece, Italy, Poland, Spain, Sweden, Switzerland and the UK. This set represents all major European regions as well as institutional and socioeconomic contexts. Samples were matched to national statistics for age, gender, region and education. Once all the missing values were removed, our study's final sample was 13,165 . To test our hypotheses, we estimated logistic regressions with and without relevant interaction effects. All models are estimated with fixed effects for countries. Poland, being the only post-communist country in the sample, is set as a reference group. Following Domanski's findings (2015), which showed a particularly low propensity to protest in post-communist countries, we expect people from other countries to have a higher inclination to engage in protest action than Poles.

We conceptualised our dependent variable as self-reported prospect behaviour and thus employ a standard prospective measure of protest activity (van Stekelenburg et al. 2011, p. 92). We relied on the prospective measure so that the time-ordering of independent and dependent variables respects the requirements of causality. We used responses to three survey items: There are different ways of trying to improve things or help prevent things from going wrong. When did you LAST do the following: - 'attend a demonstration, march or rally', - 'join a strike', - 'join an occupation, sit-in or blockade? and created a dichotomous variable denoting whether the respondent declared that she or he could (or could not) see herself or himself doing at least one of these activities in the future.

We are aware of the methodological limitations of relying on self-reported projected engagement in protest activities (Giugni and Grasso 2015a, p. 238). We also acknowledge the scholarship on the role of individual and collective resources in protest activities, which suggests that general willingness to protest-particularly among people with serious financial problems-may not translate into actually engaging in behaviour due to scarce assets. However, we believe that our survey question refers to prospect behaviour and not a general willingness to protest. We interpret the answers 'I could see myself doing this in the future' and 'I would never see myself doing this in the future' as two values (options) of a dichotomous indicator of propensity to protest - an indicator of self-assessed capability to take part in a demonstration, protest or occupation and not as an individual counterfactual wish.

It is important that only respondents who did not participate in any of these protest activities in the past were asked about their prospective protest behaviour. Thus, our main models include only respondents with no past protest experience $(N=6805)$. Nevertheless, in order to check if this choice could affect the findings (bringing bias), in Table 3 in the "Appendix" we also estimated models for the whole sample with a dependent variable coded 0 for all those who have never participated in a protest and do not see themselves doing so in the future, and 1 for those who have participated in protests in the past or envisage themselves doing so in the future $(N=13,165)$. Here, we interpret past protesting behaviour as a proxy for similar prospective behaviour in future. The results from the latter are effectively the same as for the former (we report these in the "Appendix").

The first of our two key independent variables-being denied a benefit or service-is operationalised as respondents' answer to the question: 'During the last 12 months have you been denied access to a public social service or benefit that you 
think you should receive?' This question operationalises neither the simple termination of a benefit or provision of a service, nor the legitimate (in the respondents' opinion) fact of not meeting the criteria to receive support. Our question refers to the perception of two violations: of a citizen's own social rights, and of injustice in how the welfare state functions. This perception may occur amid the reception of (other) benefits/services from the welfare state.

The second major independent variable is the study-receiving a social benefit/ service-is operationalised based on the question: 'During the last 12 months have you used/received any of the following kinds of public support/benefits?' The items included (1) unemployment benefit or free skills training, (2) social housing or housing support/benefit, (3) child/maternity/family/one parent family support/benefit, (4) sickness/mobility/invalidity/disabled person's pension/benefit, (5) in-kind support (e.g. food/free meals/clothing), (6) help from home care services (e.g. family assistant/social worker). We constructed a binary variable, where 1 ('yes') denoted the respondent had received any of the above benefits or services. Including various social benefits or services, both universal and means-tested, is justifiable for two reasons. First, contrary to national studies on specific social policy programs, such as those of Soss (1999), Mettler (2002) or Campbell (2003), our research is based on an international survey conducted in the nine European countries. Even selecting certain instruments would mean examining the various ways and forms in which they were used in those countries. Moreover, the growing number of services and benefits is often a mix of universal and means-tested measures (as in the case of family benefits, where diverse criteria apply to consecutive children in the family), whereas various conditions are applied to obtain most of the above-mentioned services (care services, in-kind support). Second, one of the major aims of our study is to investigate the impact of being denied a service/benefit and how that experience interacts with social transfers/services receiving than testing the already wellresearched impact of certain welfare state measures on political participation.

Since we hypothesise that the effect of being denied or provided with a benefit and their interaction may be modified by (be dependent upon) the occurrence of having serious financial problems, two groups of respondents can be distinguished: those with serious financial problems (those struggling to make ends meet, the living in poverty) and the rest of the population (not living in poverty). In order to identify the subpopulation of people struggling to make ends meet (the living in poverty), we used individual responses to the survey question (the same one used in Eurobarometer): 'Which of the following best describes how your household is currently keeping up with all its bills and credit commitments'. The responses included such answers as 'I am/we are keeping up without any trouble', 'I am/we are keeping up but struggle to do so from time to time' 'I am/we are keeping up but it is a constant struggle', 'I am/we are falling behind with some bills/credit commitments'; 'I am/we are having real financial problems and have fallen behind with many bills and credit commitments'. The latter three responses were chosen to identify people having serious financial problems (the living in poverty). This group consisted of $26.28 \%$ of the total sample and mirrors a similar proportion as those populations identified as living in poverty or at risk of poverty according to Eurostat for the same year and group of countries (23.03\%; Eurostat 2017). 
Table 1 Variable descriptive statistics

\begin{tabular}{lrrrc}
\hline Variable name & Min & Max & Mean & SD \\
\hline Sees him/herself protesting in future & 0 & 1 & 0.4061 & 0.4911 \\
Age & 18 & 95 & 45.68 & 15.693 \\
Gender & 0 & 1 & 0.5392 & 0.4984 \\
Less than secondary education & 0 & 1 & 0.2833 & 0.4506 \\
Unemployed & 0 & 1 & 0.1043 & 0.3057 \\
Poor (with serious financial problems) & 0 & 1 & 0.2628 & 0.4402 \\
Internal political efficacy & 1 & 5 & 3.1835 & 0.9156 \\
External political efficacy & 1 & 5 & 3.3704 & 0.8151 \\
Interested in politics & 0 & 1 & 0.573 & 0.4947 \\
Left-Right orientation & 0 & 10 & 3.7958 & 1.7141 \\
Autonomy & 0 & 10 & 4.5896 & 1.5778 \\
Additive group membership & 0 & 12 & 0.5029 & 1.1103 \\
Has been denied social welfare (benefits or services) & 0 & 1 & 0.0904 & 0.2868 \\
Has received social welfare (benefits or services) & 0 & 1 & 0.2696 & 0.4438 \\
$\mathrm{~N}$ & 6809 & & & \\
\hline
\end{tabular}

For the other (control) variables, we used standard indicators for such socioeconomic explanatory factors as age, gender, education and unemployment status, as well as political ones including internal and external political efficacy, political interest, left-right orientation, liberal autonomy and group membership (see e.g. Giugni and Grasso 2017). All the details of the construction of other control variables can be found in the "Appendix". The descriptive statistics for all the variables used in our models are presented in Table 1.

\section{Results}

Table 2 shows the results of a series of logistic regressions. The results of the estimated regression models confirm the traditionally negative impact of age, as well as being female, on prospective protest activities. Experiencing unemployment proved not to have a significant effect on prospective protest behaviour, while having serious financial problems has a significant, positive effect, except in the final model with all interactions included. The latter finding suggests that being poor does not have a significant effect on prospective protest behaviour among those who neither have experience with receiving social welfare nor with being denied it. As far as personal political characteristics are concerned, as expected, political interest, internal political efficacy, left-right orientation and civil society group membership have a significant positive impact on the prospective propensity to protest in all estimated models. Also, according to our expectations, country fixed effects are all significant and positive.

The main effect of being denied a benefit/service (M2) supports our first hypothesis-namely that being denied a service or benefit increases the likelihood of 


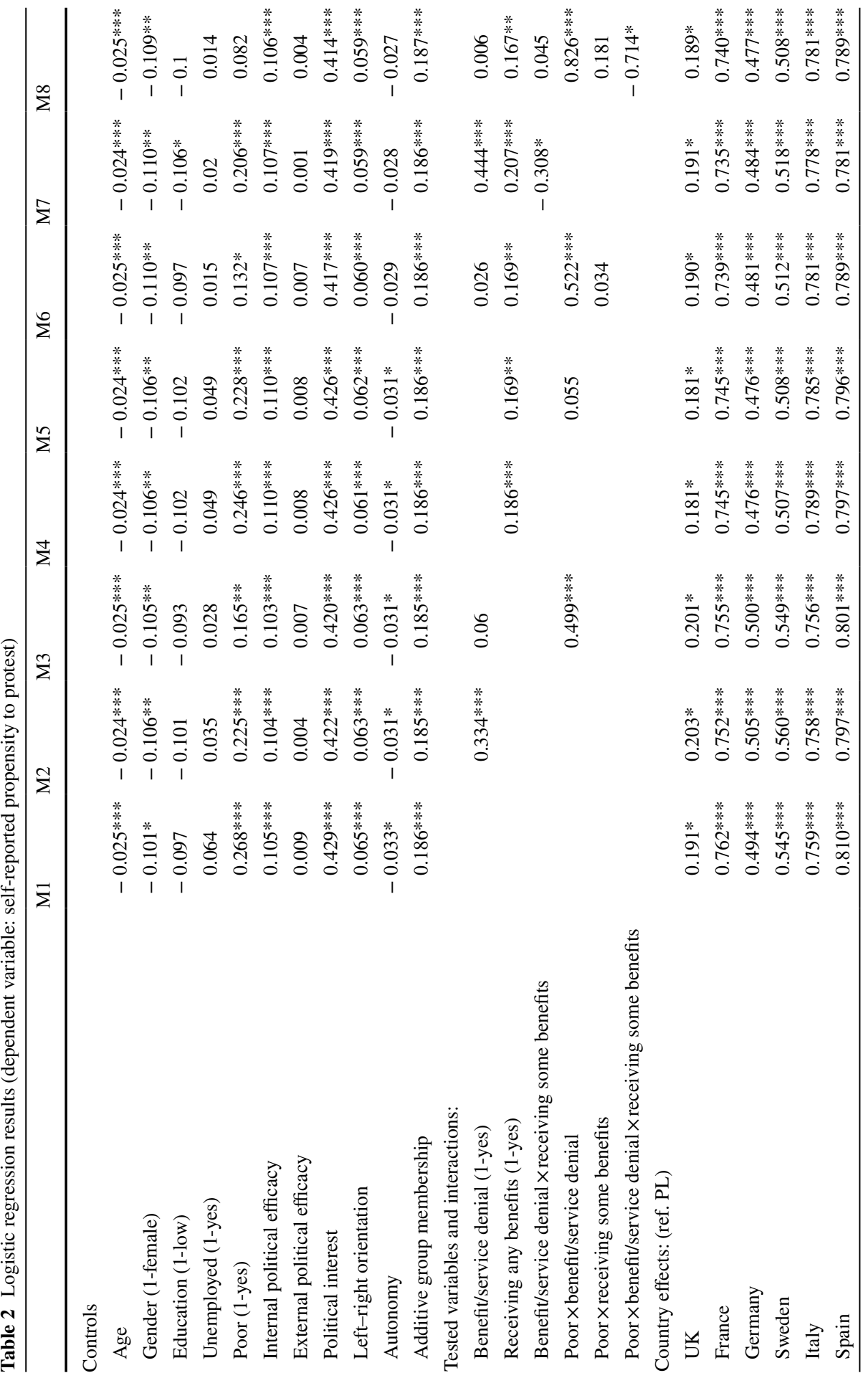

尔 


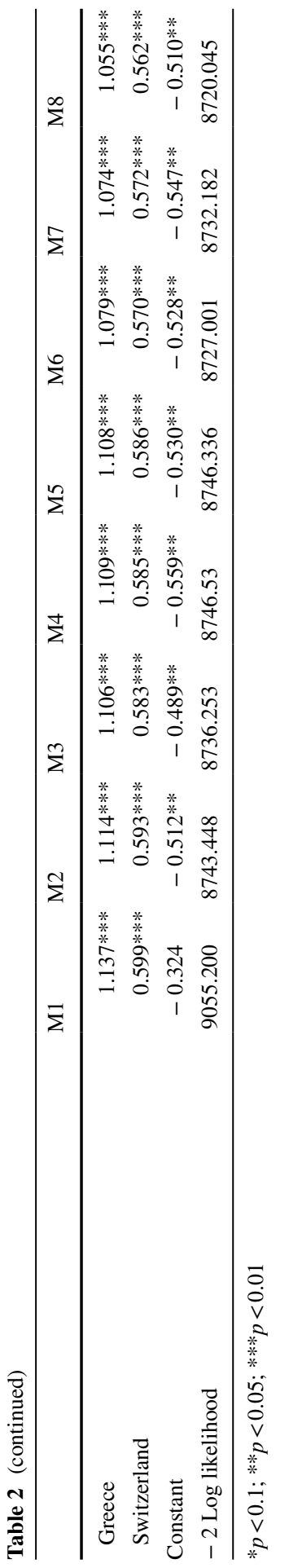


prospective protest behaviour. Such experience makes one more likely to envisage oneself protesting in future. However, if the interaction effect with being poor is added (M3, M6), we discover that the significant effect of benefit/service denial takes place only among the population that struggles to make ends meet. This lends support to our second hypothesis. Among the poor, those who have an experience of benefit/service denial have $74.9 \%$ higher odds of prospective protest behaviour than those who do not have the experience of benefit or service denial (other variables held constant; see M3).

The main effect of receiving benefits provides support for our third hypothesis: that receiving service increases the likelihood of prospective protest behaviour (M4). This is true both among the poor and non-poor population (M5, M6). In other words, regardless of the individual's financial situation, the fact of receiving a benefit/service increases the propensity of prospective protest behaviour. This supports our fourth hypothesis. Among the poor, those who have an experience of benefit or service receiving have 25.1 per cent higher odds of prospective protest behaviour than those who do not have the experience of benefit/service receiving (other variables held constant; see M5). Among the non-poor those who had an experience of benefit/service receiving have 18.4 per cent higher odds of prospective protest behaviour than those who do not have that experience (other variables held constant; see M5).

The model with the interaction effect between being denied and provided with social welfare (M7) provides support for our final hypothesis. The propensity to protest among people who have the experience of social welfare denial but who also receive social benefits or services is lower than among those who have the sole experience of being denied social welfare. As we show in our final model (M8), this moderating effect is, however, significant only among the people living in poverty, which makes sense as only among this group do we find a significant positive effect of the experience of social welfare denial on the propensity to protest (M3, M6). Among people living in poverty and having the experience of social welfare denial, those who also receive social benefits or services have 27.5 per cent lower odds of prospective protest behaviour that those who have the experience of social welfare denial but who do not receive social benefits or services (other variables held constant; see M8).

\section{Discussion and conclusion}

This study provides evidence that among the poor, being denied social benefits or services increases the propensity to protest. It also sheds light on the importance of receiving social benefits or services when, at the same time, one is refused social welfare.

We have found that the impact of being denied benefits or services on the propensity to protest is positive, though proves statistically significant only among those who struggle to make ends meet. There are two reasons for this. First, the 
other sources of financial and/or social capital the wealthy enjoy diminishes the importance of potential loss of social welfare. Second, although the wealthy say they did not receive a benefit or service they should have, their good living conditions may lead to the assumption that the denial could have been procedurally unjust but socially legitimate. This explanation is consistent with previous findings of other studies on relative deprivation leading to protest (Muñoz et al. 2014; Lorenzini and Giugni 2015; Dodson 2016).

We have also found that those citizens who benefit from the welfare state are more likely to engage in protest than those who have no experience with it. This finding speaks for the presence of the resources effect of social benefits or services numerous other studies have found-money, time, social contacts and information about where and with whom to protest (McCarthy and Zald 1977; Campbell 2003; Klandermans 1997) all compel individuals to engage in protest activity. That compulsion may be particularly a plausible result of a resources effect based on social networks and access to information, rather than the impact of receiving money. That this result is also seen as significant among better-off citizens who have not been denied benefits or service further leads us to this conclusion.

The respondents living in poverty who have both positive and negative experiences with the welfare state turned out to be less prone to engage in protest activity than those who have experienced only denial. Thus, we argue that receiving a service or benefit suppresses the inclination to protest among poor people who have been denied support from the state. This may be explained by the cognitive-emotional interaction effect of social benefits and services when received in the context of social welfare denial (Pierson 1993; Lynch and Myrskyla 2009; van Stekelenburg et al. 2011). It is based on the contention that the beneficiary is worthy and deserving of welfare state support, a message which supposedly has the potential to change their interpretation of (simultaneous, previous or subsequent) being denied social rights. Moreover, in the light of the scholarship that has been produced to date on protest motivation, we suppose that receiving social welfare alleviates anger-based and ideological motivations. This mechanism-changing interpretation of how the welfare state works and the moderation anger-is independent from the political efficacy-based mechanism which we control for in our models.

Among the limitations of our research is the lack of information on sequence in which benefits are received or denied. In other words, more detailed research would be needed to determine if the situation in which obtaining social welfare following a previous denial could have a different effect on the motivation to protest than does the fact of being denied after receiving social welfare. Moreover, we acknowledge Muñoz et al.'s (2014) remark that feelings of injustice and anger as an incentive to protest might fade with time, in contrast to the probably 
longer-lasting empowering impact of receiving social welfare. Additionally, we neither differentiated between types of benefits and services granted and/or denied, nor between the types of welfare state in which the respondents from the nine countries live. As the policy feedback scholarship we have presented proves, means-tested and universal benefits may have different impacts on participation (Campbell 2012; Mettler 2005; Soss 2000). At the same time, we may expect that the interaction between different types of help granted and denied may be specific. Thus, further studies would be required to produce a more nuanced picture of the complex impact-positive in some contexts, negative in others-social welfare can have on the propensity to protest.

Acknowledgements The authors would like to thank Christian Lahusen and Luke Temple for their insightful internal reviews, as well as all other LIVEWHAT team members for their supportive comments to the early draft of the article. Results presented in this article have been obtained within the project "Living with Hard Times: How Citizens React to Economic Crises and Their Social and Political Consequences" (LIVEWHAT). This project was funded by the European Commission under the 7th Framework Programme (grant agreement no. 613237). This article was partially financed by the Polish Ministry of Science and Higher Education 2014-2016 fund, granted for an international co-financed project.

Open Access This article is distributed under the terms of the Creative Commons Attribution 4.0 International License (http://creativecommons.org/licenses/by/4.0/), which permits unrestricted use, distribution, and reproduction in any medium, provided you give appropriate credit to the original author(s) and the source, provide a link to the Creative Commons license, and indicate if changes were made.

\section{Appendix: The construction of control variables}

(1) Age - treated as a continuous variable indicating the number of years of age completed.

(2) Gender-measured as a dummy variable, where the reference category is male, and 1 is female.

(3) Education-operationalised as a dummy variable, where 1 indicates lower education, and the reference category denotes secondary education or higher.

(4) Unemployment - operationalised as a dummy variable, where one indicates those declaring themselves unemployed on the labour market and the reference category denotes all other economic groups.

(5) Internal efficacy - operationalised based on the average score for three questions, where respondents indicated the degree to which they (dis)agree with the following statements: I consider myself well qualified to participate in politics; I feel that I have a pretty good understanding of the important political issues facing the [country name]; I think that I am at least as well informed about 
politics and government as most people. The answers were given based on a 5-point scale where 1 denoted "disagree strongly" and 5 "agree strongly".

(6) External efficacy-operationalised based on the average score for three questions, where respondents indicated the degree to which they (dis)agree with the following statements: Public officials don't care much what people like me think; People like me don't have any say about what the government does; Sometimes politics and the government seem so complicated that a person like me can't really understand what's going on. The answers were given based on a 5-point scale where 1 denoted "disagree strongly" and 5 "agree strongly".

(7) Political interest-operationalised as a dummy variable where 1 denoted a person interested in politics. This value was assigned to those respondents who answered very interested or quite interested to the question: How interested, if at all, would you say you are in politics?

(8) Liberal autonomy-operationalised based on the average score for the answers to five questions, where respondents positioned themselves on a scale of which the two ends represented polarised stands on the following issues: (1) A woman has to have children in order to be fulfilled versus $A$ woman can be fulfilled through her professional career; (2) A woman who does not want to have a child should be allowed to have a free and safe abortion versus Abortion should not be allowed in any case; (3) Children should be taught to obey authority versus Children should be encouraged to have an independent judgement; (4) People who break the law should get tougher sentences vs Tougher sentences do not contribute to reducing criminality; (5) Homosexual couples should be able to adopt children vs Homosexual couples should not be allowed to adopt children under any circumstances.

(9) Left-right orientation-operationalised based on the average score for the answers to five questions, where respondents positioned themselves on a scale of which the two ends represented polarised stands on the following issues: (1) Incomes should be made more equal vs We need larger income differences as incentives; (2) People should take more responsibility to provide for themselves vs The government should take more responsibility to ensure that everyone is provided for; (3) People who are unemployed should have to take any job available or lose their unemployment benefits vs People who are unemployed should have the right to refuse a job they do not want; (4) Competition is good. It stimulates people to work hard and develop new ideas vs Competition is 


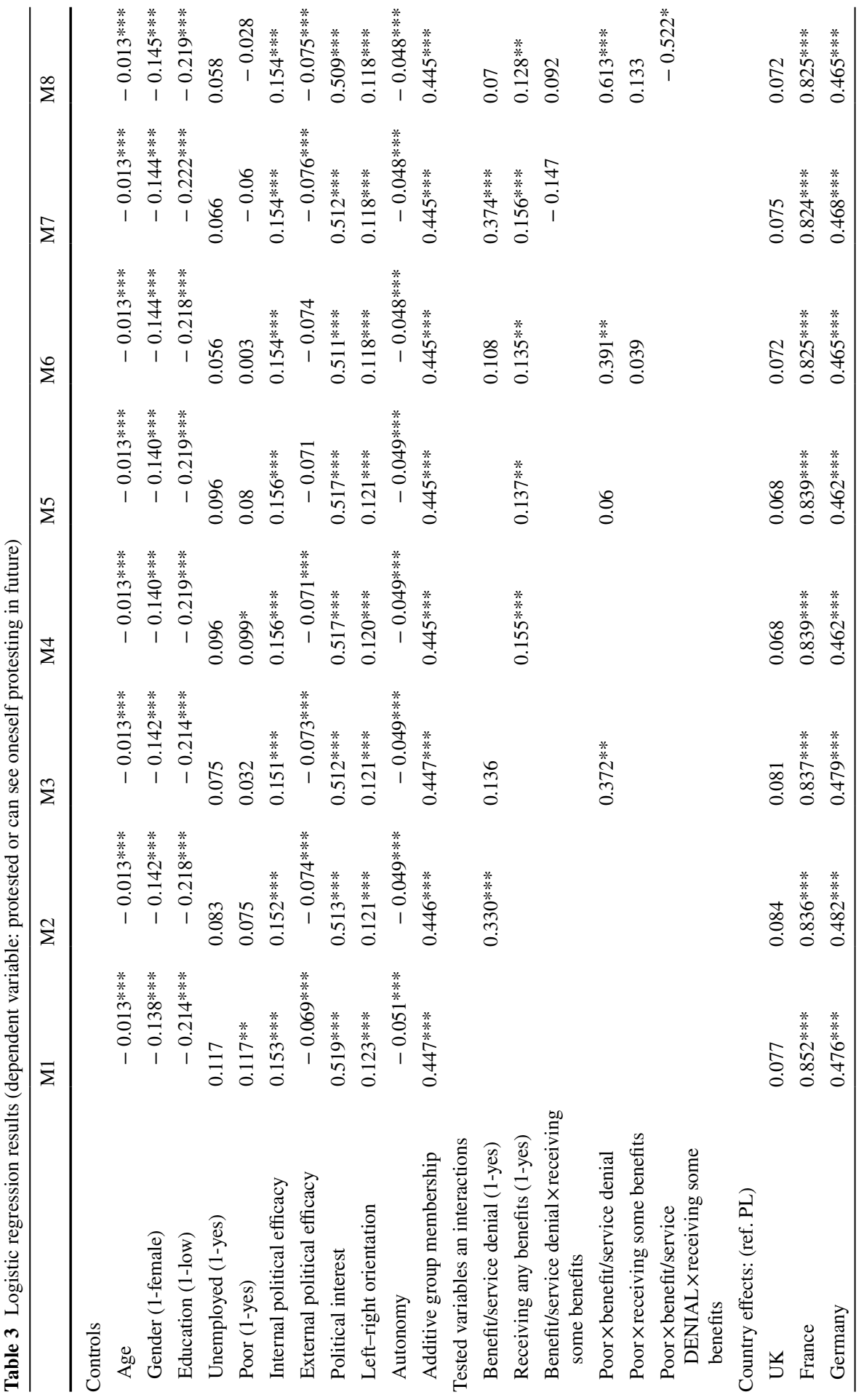

尔 


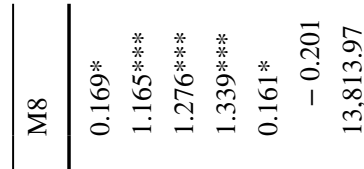

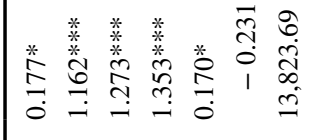

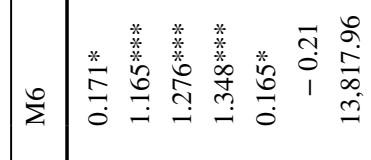

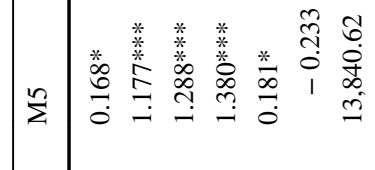

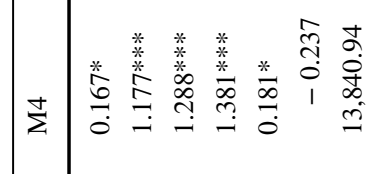

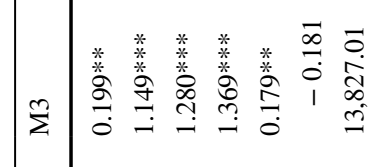

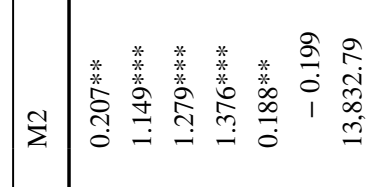

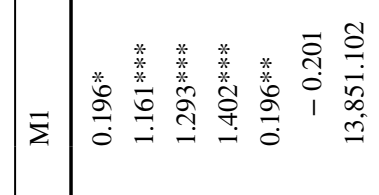

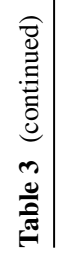

$\sigma$
$\dot{v}$
$v$
$*$
$*$
$*$
$\ddot{\delta}$
$\dot{0}$
$v$
$v$
$*$
$\ddot{E}$
$\dot{0}$
$v$
$*$ 
harmful. It brings out the worst in people; 5) Government should decrease taxes a lot and spend much less on social benefits and services vs Government should increase taxes a lot and spend much more on social benefits and services;

(10) Additive group membership - operationalised as the number of memberships declared by the respondent with reference to 12 different political or social organisations.

\section{References}

Avram, S. 2016. Social assistance performance in Central and Eastern Europe: A pre-transfer post-transfer comparison. Journal of European Social Policy 26 (5): 428-441.

Béland, D. 2010. Reconsidering policy feedback: How policies affect politics. Administration and Society 42 (5): 568-590.

Bermeo, N., and L.M. Bartels. 2014. Mass politics in tough times. In Mass politics in tough times: Opinions, votes and protest in the great recession, ed. N. Bermeo, and L.M. Bartels, 1-39. Oxford: Oxford University Press.

Brady, H.E., S. Verba, and K.L. Schlozman. 1995. Beyond SES: A resource model of political participation. American Political Science Review 89 (2): 271-294.

Campbell, A.L. 2002. Self-interest, Social Security, and the distinctive participation patterns of senior citizens. American Political Science Review 96: 565-574.

Campbell, A. 2003. How policies make citizens: Senior political activism and the American Welfare State. Princeton: Princeton University Press.

Campbell, A. 2012. Policy makes mass politics. Annual Review of Political Science 15 (1): 333-351.

Cinalli, M., and P. Vasilopoulos. 2015. Feelings of hardship and anxiety for contentious politics: Economic crisis and unemployed youth in France. In Austerity and protest. Popular contention in times of economic crisis, ed. Marco Giugni, and Maria Grasso, 217-230. Farnham: Ashgate.

Della Porta, D., and Mattoni, A. 2014. Patterns of diffusion and the transnational dimension of protest in the movements of the crisis: an introduction. In Spreading Protest: Social Movements in Times of Crisis, 1-21.

Diani, M., and D. McAdam. 2003. Social movement perspective. Oxford: Oxford University Press.

Dodson, K. 2016. Economic threat and protest behavior in comparative perspective. Sociological Perspectives 59 (4): 873-891.

Domański, H. 2015. Patterns of contentious activity. In After the soviet empire: Legacies and pathways, ed. S. Eliaeson, L. Harutyunyan, and L. Titarenko, 311-335. Leiden: Brill.

Dowding, K., and P. John. 2008. The three exit, three voice and loyalty framework: A test with survey data on local services. Political Studies 56 (2): 288-311.

Eurostat. 2017. People at risk of poverty or social exclusion by age and sex[ilc_peps01]. http://appss o.eurostat.ec.europa.eu/nui/submitViewTableAction.do.

Farah, B., S. Barnes, and M. Heunks. 1979. Political dissatisfaction. In Political action: Mass participation in five western democracies, ed. S. Barnes, M. Kaase, et al., 409-448. Beverley Hills: Sage.

Folger, R. 1986. Rethinking equity theory: A referent cognitions model. In Justice in social relations, ed. H.W. Bierhoff, R.L. Cohen, and J. Greenberg, 145-162. New York: Plenum.

Genovese, F., P. Schneider, and P. Wassmann. 2016. The Eurotower Strikes Back: Crises, adjustments, and Europe's austerity protests. Comparative Political Studies 49 (7): 939-967.

Giugni, M., and M. Grasso. 2015a. Conclusion: Austerity and protest. In Austerity and protest-popular contention in times of economic crisis, ed. M. Giugni, and M. Grasso, 231-240. Farnham: Ashgate.

Giugni, M., and M. Grasso. 2015b. Introduction: Austerity and protest: Debates and challenges. In Austerity and protest-popular contention in times of economic crisis, ed. Marco Giugni, and Maria Grasso, 1-15. Farnham: Ashgate.

Giugni, M., and M. Grasso. 2017. Blame and contention: How perceptions of the government's role in the economic crisis shape patterns of political action. Acta Politica. https://doi.org/10.1057/s4126 9-017-0073-x. 
Grasso, M., and M. Giugni. 2016. Protest participation and economic crisis: The conditioning role of political opportunities. European Journal of Political Research 55 (4): 663-680.

Gurr, T. 1970. Why men rebel. Princeton: Princeton University Press.

Klandermans, B. 1997. The social psychology of protest. Oxford: Basil Blackwell.

Klandermans, B., J. van Stekelenburg, and M.-L. Damen. 2015. Beneficiary and conscience constituencies: On interests and solidarity. In Austerity and protest. Popular contention in times of economic crisis, ed. M. Giugni, and M. Grasso, 155-169. Farnham: Ashgate.

Kornhauser, W. 1959. The politics of mass society. Glencoe, IL: Free Press.

Kriesi, H., and A. Westholm. 2007. Small-scale democracy: The determinants of Action. In Citizenship and involvement in European democracies, ed. J. van Deth, J.R. Montero, et al. New York: Routledge.

Kumlin, S. 2014. How the welfare state shape the democratic public: Policy feedback, participation, voting and attitudes. Cheltenham: Edward Elgar.

Lorenzini, J., and M. Giugni. 2015. Welfare institutions, resources and political learning. Interacting with the state as an incentive for political participation of long-term unemployed youth. Partecipazione $e$ Conflitto 8 (3): 814-844.

Lynch, J., and M. Myrskyla. 2009. Always the third rail? Pension income and policy preferences in European democracies. Comparative Political Studies 42: 1068-1097.

Marchal, S., I. Marx, and N. Van Mechelen. 2014. The great wake-up call? Social citizenship and minimum income provisions in Europe in Times of Crisis. Journal of Social Policy 43 (02): 247-267.

Marien, S., M. Hooghe, and E. Quintelier. 2010. Inequalities in non-institutionalised forms of political participation: A multi-level analysis of 25 countries. Political Studies 58 (1): 187-213.

McCarthy, J.D., and M.N. Zald. 1977. Resource mobilization and social movements: A partial theory. American Journal of Sociology 82 (6): 1212-1241.

Mettler, S. 2002. Bringing the state back into civic engagement: Policy feedback effects of the G.I. bill for World War II veterans. American Political Science Review 96 (2): 351-365.

Mettler, S. 2005. Soldiers to citizens: The G.I. Bill and the making of the greatest generation. New York: Oxford University Press.

Muñoz, J., G. Rico, and E. Andiuza. 2014. Empowering cuts? Austerity policies and political involvement in Spain. In How welfare states shape the democratic public: Policy feedback, participation, voting, and attitudes, ed. S. Kumlin, and I. Stadelmann-Steffen, 19-40. Cheltenham: Edward Elgar.

Norris, P. 2002. Democratic phoenix: Reinventing political activism. Cambridge: Cambridge University Press.

Patashnik, E., and J.E. Zelizer. 2009. When policy does not remake politics: The limits of policy feedback. Prepared for presentation at the Annual Meeting of the American Political Science Association, Toronto, Canada, September 3-6, 2009.

Patashnik, E., and J. Zelizer. 2013. The struggle to remake politics: Liberal reform and the limits of policy feedback in the contemporary American state. Perspectives on Politics 11 (4): 1071-1087.

Pierson, P. 1993. When effect becomes cause: Policy feedback and political change. World Politics 45 (04): 595-628.

Quaranta, M. 2014. Collective and Private resources and the inequalities of non-violent political protest in European countries. Journal of Civil Society 10 (3): 294-316.

Rothstein, B. 2001. Social capital in the social democratic welfare state. Politics and Society 29 (2): 207-241.

Schneider, S.M., and C. Devitt. 2017. Accessing healthcare in times of economic growth and economic downturn: Evidence from Ireland. Journal of European Social Policy. https://doi.org/10.1177/09589 28717739240 .

Schur, L. 2003. Employment and the creation of an active citizenry. British Journal of Industrial Relations 41 (4): 751-771.

Solevid, M. 2009. Voices from the welfare state. Dissatisfaction and political action in Sweden. Gothenburg: University of Gothenburg.

Soss, J. 1999. Lessons of welfare: Policy design, political learning, and political action. American Political Science Review 93 (2): 363-380.

Soss, J. 2000. Unwanted claims: The politics of participation in the US Welfare System. Ann Arbor: University Michigan Press.

Szelewa, D. 2017. From implicit to explicit familialism: Post-1989 family policy reforms in Poland. In Gender and family in European economic policy, ed. D. Auth, J. Hergenhan, and B. Holland-Cunz. Basingstoke: Palgrave Macmillan. 
Taylor-Gooby, P. 2009. Reframing social citizenship. Oxford: Oxford University Press.

Teorell, J., P. Sum, and M. Tobiasen. 2007. Participation and political equality: An assessment of largescale democracy. In Citizenship and involvement in European democracies: A comparative analysis, ed. J.W. van Deth, J.R. Montero, and A. Westholm, 384-414. New York: Routledge.

van Lancker, W. 2017. Reducing inequality in childcare service use across European countries: What (if any) is the role of social spending? Social Policy \& Administration 52 (1): 271-292.

van Oorschot, W., and W. Arts. 2005. The social capital of European welfare states: The crowding out hypothesis revisited. Journal of European Social Policy 15 (1): 5-26.

van Stekeleburg, J., and B. Klandermans. 2013. The social psychology of protest. Current Sociology 61 (5-6): 886-905.

van Stekelenburg, J., B. Klandermans, and W. van Dijk. 2011. Combining motivations and emotion: The motivational dynamics of protest participation. Revista di Psicologia Social 26 (1): 91-104.

van Zomeren, M., T. Postmes, and R. Spears. 2008. Toward an integrative social identity model of collective action: A quantitative research synthesis of three socio-psychological perspectives. Psychological Bulletin 134: 504-535.

van Zomeren, M., and R. Spears. 2004. Put your money where your mouth is! Explaining collective action tendencies through group-based anger and group efficacy. Journal of Personality and Social Psychology 87 (5): 649-664.

Vanhuysse, P. 2006. Divide and pacify: strategic social policies and political protests in post-communist democracies. Budapest: Central European University Press.

Verba, S., K. Schlozman, and H. Brady. 1995. Voice and equality: Civic voluntarism in American politics. Cambridge, MA: Harvard University Press.

Vis, B., K. van Keesbergen, and A. Hemerijck. 2013. The triple crisis and welfare state reform: Is retrenchment really the only game left in town? Paper presented at the University of Southern Denmark, Odense, April 12-13, 2013.

Yerkes, M., and R. van der Veen. 2011. Crisis and welfare state change in the Netherlands. Social Policy \& Administration 45 (4): 430-444. 